\title{
Selected methods of converting solar energy into electricity - comparative analysis
}

\author{
Kamil Gawkowski ${ }^{1, *}$, and Jarostaw Sikora ${ }^{1,2}$ \\ ${ }^{1}$ The State School of Higher Education in Chelm, The Institute of Technical Sciences and Aviation, \\ Pocztowa 54, 22-100 Chełm \\ ${ }^{2}$ Lublin University of Technology, Department of Automatics and Metrology, Nadbystrzycka 38 A, \\ 20-618 Lublin
}

\begin{abstract}
This article presents selected methods of converting solar energy into electricity: photovoltaic cells (PV), converters which use photon-enhanced thermionic emission (PETE), and near-field enhanced thermionic energy conversion systems (NETEC). PETE and NETEC systems are innovative solutions that use the thermionic emission phenomenon and can replace photovoltaic generation of electricity. We did a comparative analysis of such issues as: structure, principle of operation, working temperature and with particular emphasis - efficiency. A comparison of these parameters is shown in the graphs and summarized in the table. Based on the analysis, we have drawn conclusions about previous achievements and development perspectives in the field of converting methods.
\end{abstract}

\section{Introduction}

Percentage share of renewable energy sources in total electricity generation is still slight. The increase in this share is very important for reduction of environmental pollution, and energy security in the long-term perspective. Especially, the use of solar energy requires a refinement and improvement of converting efficiency. In this article we made a comparison of converting methods: photovoltaic cells (PV), converters which use photonenhanced thermionic emission (PETE), and near-field enhanced thermionic energy conversion systems (NETEC).

\section{Principle of operation}

PV cells are fundamentally made up of a PN joint. The schematic diagram is presented in Fig. 1.

\footnotetext{
${ }^{*}$ Corresponding author: kgawkowski@pwsz.chelm.pl
} 


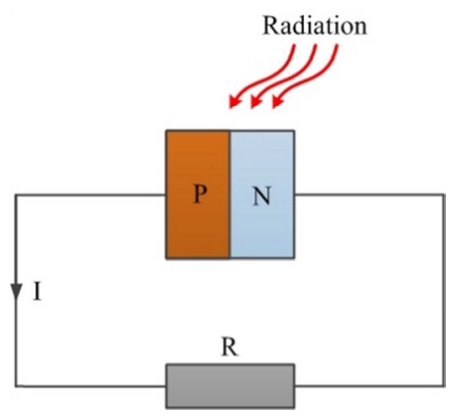

Fig. 1. PV cell - electricity generation principle.

PV cell generates voltage only if photon flux energy is greater than the semiconductor bandgap. When a load is connected to the terminals of the " $p "$ and " $n$ " areas, an electric current will flow. Electricity generation requires a large amount of costly solar cells, because intensity of solar radiation is low on the Earth (usually less than $1,000 \mathrm{~W} / \mathrm{m}^{2}$ ) $[1,2]$. Reduction of number of solar cells and an increase in the conversion performance can be achieved by the application of concentrating PV. This solution uses reflective mirrors (or refractive optic lenses) to concentrate sunlight onto solar cells [3, 4]. As the temperature of PV cell increases, the output voltage and conversion efficiency decrease. This is a significant disadvantage, especially in the summer, which is the sunniest season of the year in the northern hemisphere of the Earth.

The solution for the problem of heating and decreasing efficiency of PV cells may be the use of a PETE converter [5], which converts solar energy into electricity using solar photovoltaic and thermionic emission phenomena. An increase of cell temperature is potentially advantageous, because it increases the share of thermionic emission in the energy balance. PETE converter consists of semiconductor cathode and metallic anode. They are separated with vacuum or gas (usually cesium vapor). The band scheme of PETE converter is presented in Fig. 2.

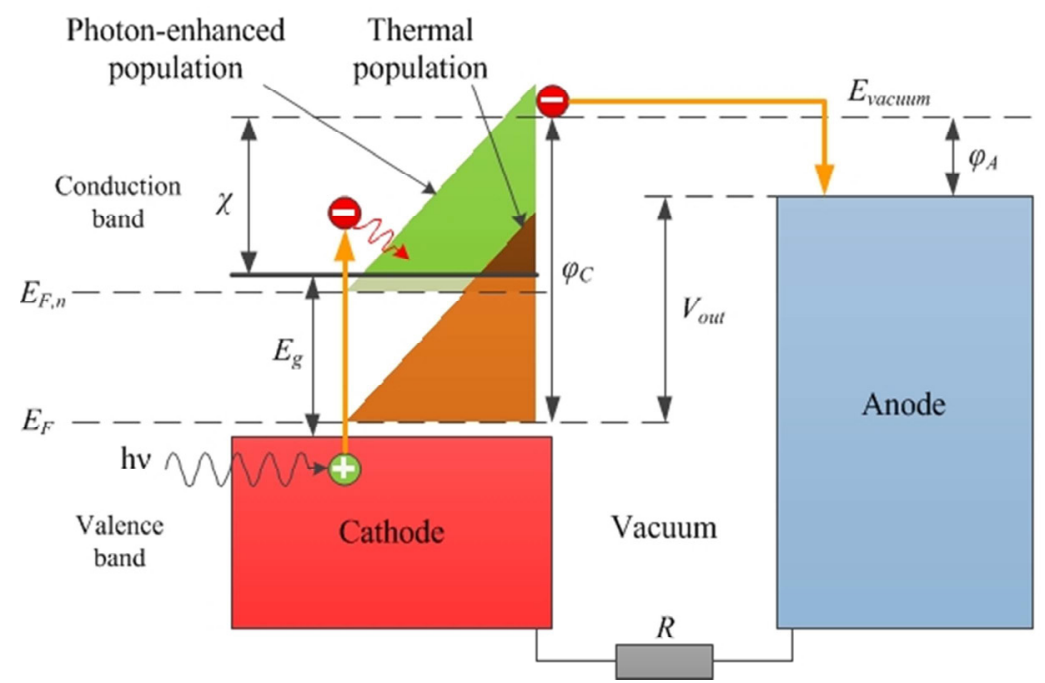

Fig. 2. Band scheme of PETE converter, $h v-$ a quantum of light, $E_{g}-$ energy bandgap, $E_{F}-$ Fermi level, $E_{F, n}$ - quasi Fermi level, $\chi$ - electron affinity, $\varphi_{C}$ - cathode work function, $\varphi_{A}$ - anode work function, $V_{\text {out }}$ - output voltage that can be set aside for the receiver $R[5,6]$. 
Emission of electron into the vacuum area and then to the anode takes place by a part of the photon energy needed to excite the electron from the valence band to the conduction band. It also takes place by part of the photon energy, in the form of thermal energy, necessary to overcome energy barrier defined by electron affinity of the cathode material. In this way, the energy of light quanta is used to a much higher degree than photovoltaic processing. Electrons in the valence band are excited into the conduction band under the influence of absorbed photons, whose energy $h v$ is greater than the semiconductor bandgap $E_{g}$. It causes a significant increase in their concentration in the conduction band [7].

Surplus of photons energy, in relation to the semiconductor bandgap $E_{g}$, is transmitted to the crystal lattice in the form of thermal energy (in the process of thermalization). Electrons, whose energy is greater than the electron affinity $\chi$ of cathode material, are emitted to the vacuum and received by the anode.

The output voltage, according to the diagram shown in Fig. 2, equals:

$$
V_{\text {out }}=\varphi_{C}-\varphi_{A}
$$

The increase in the value of the quasi-Fermi level, due to the increase in the concentration of photoelectrons in the conduction band, increases the density of the thermionic emission current. In the case of PETE cells, the cathode work function $\phi_{K}$ should equal $1.4 \mathrm{eV}$, similarly as PV cells $[6,8]$. The work function of anode $\phi_{A}$ should be as small as possible to obtain the maximum output voltage.

NETEC system is the solution to convert heat power to electricity directly from heat sources, which have temperature in the range of $800-1,600 \mathrm{~K}$. It is made of $p$-type lowbandgap semiconductor cathode (such as InSb, GaSb or InAs) and metallic anode, separated with a vacuum gap. The scheme of NETEC system is presented in Fig. 3. Subwavelength gap distance between cathode and heat source (thermal emitter) is the exceptional feature of the NETEC.

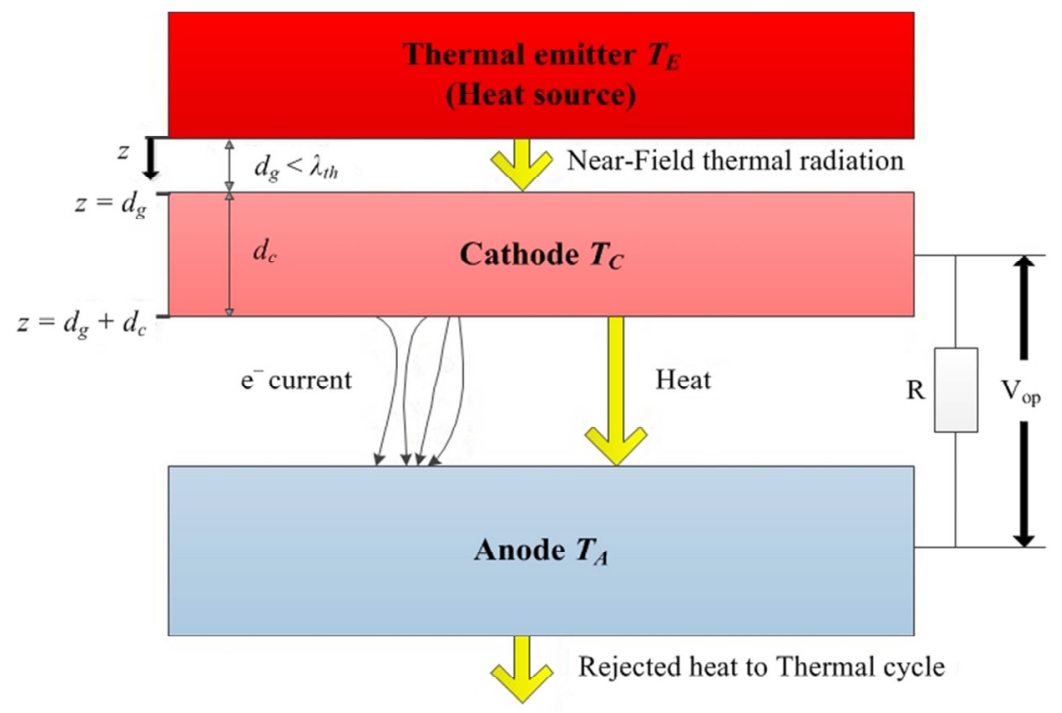

Fig. 3. Scheme of a NETEC system representing its carrier transport mechanisms and heat transfer (not scaled) [9], $d_{g}-$ gap distance between the cathode and a thermal emitter, $d_{c}-$ thickness of the cathode. 
Fig. 4. shows the energy barriers and work functions for either the anode and cathode.

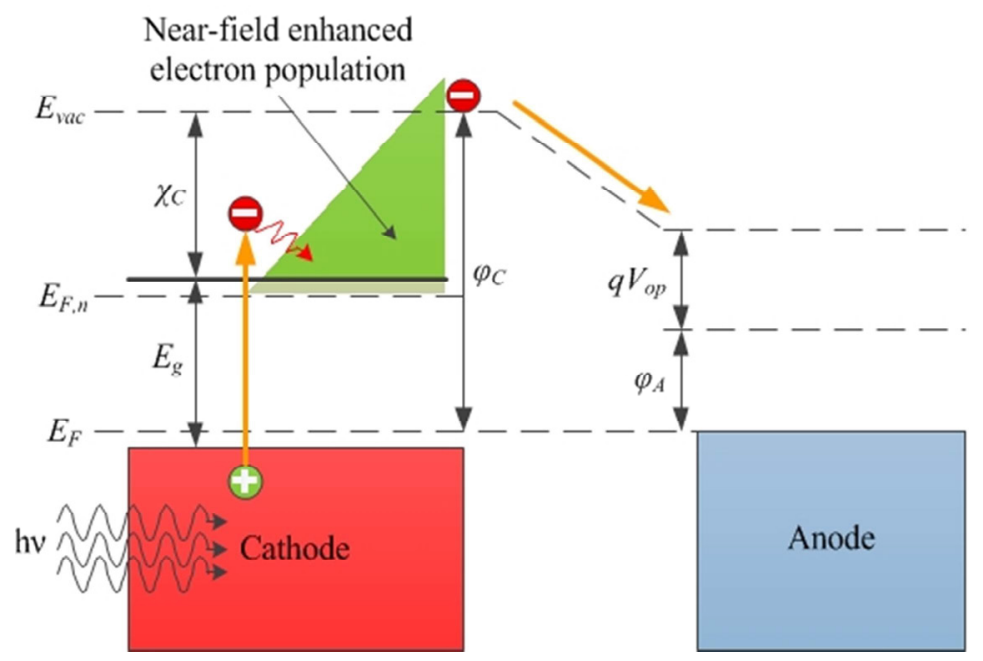

Fig. 4. Energy graph of NETEC converter [9], $h v$ - a quantum of light, $E_{g}$ - energy bandgap, $E_{F}$ - Fermi level, $E_{F, n}-$ quasi Fermi level, $\chi_{C}-$ cathode electron affinity, $\varphi_{C}-$ cathode work function, $\varphi_{A}-$ anode work function.

NETEC converter combines near-field thermal radiation with photon-enhanced thermionic energy conversion. Photon-enhanced thermionic emission make use of photon energy absorption by illumination of p-type semiconductor cathode. An increase of electron concentration in the conduction band is caused by electrons photoexcitation. Additionally, overflow of photon energy above the bandgap is converted to heat through thermalization, which contributes to the thermal excitation of electrons. Another heat source to the cathode is the intromission of sub-bandgap photon energy because of lattice vibrations or impurities. A significant quantity of electrons can be photoexcited by near-field thermal radiation owing to subwavelength gap distance between thermal emitter and cathode. It contributes to amplification of thermionic current density.

\section{Conversion efficiency}

Efficiency is defined as the ratio of the generated electrical power $P$ to the supplied thermal power $Q$ :

$$
\eta=\frac{P}{Q}
$$

For the ideal PV cell, maximum efficiency is about $42 \%$ (energy bandgap $E_{g} \approx 1.15 \mathrm{eV}$, anode temperature $T_{A}=450 \mathrm{~K}$, light concentration: $\left.\times 3000\right)$ [5].

For PETE converter $(\mathrm{GaN})$, maximum efficiency is about $48 \%$ (energy bandgap $E_{g} \approx 1.4 \mathrm{eV}$, anode temperature $T_{A}=450 \mathrm{~K}$, light concentration: $\times 3000$ ) [5].

In the case of NETEC system, its energy conversion efficiency should be defined as the ratio of the electrical power output, $P_{\text {NETEC }}$, to the heat input to the NETEC system, or nearfield thermal radiation absorbed by the cathode, $Q_{E \rightarrow C}[9]$ :

$$
\eta_{N E T E C}=\frac{P_{N E T E C}}{Q_{E \rightarrow C}}
$$


For NETEC system, maximum efficiency is about $44 \%$ (cathode electron affinity $\chi_{\mathrm{C}} \approx 1.4 \mathrm{eV}$, emitter temperature $T_{E}=2,000 \mathrm{~K}$, anode temperature $T_{A}=300 \mathrm{~K}$, anode work function $\varphi_{A}=0.7 \mathrm{eV}$, the vacuum gap distance between emitter and cathode $d_{g}=100 \mathrm{~nm}$, thickness of the cathode $d_{c}=1.5 \mu \mathrm{m}$, doping concentration of the cathode: $2.4 \times 10^{18} \mathrm{~cm}^{-3}$, cathode material: p-doped $\operatorname{In}_{0,53} \mathrm{Ga}_{0,47} \mathrm{As}$ ) [9]. The above results do not take into account the impact of space charges between the cathode and anode of NETEC system, which cause the repelling between the electrons traversing the gap $[10,11,12]$. Based on results obtained in papers [5, 9], the dependences of efficiency on temperature for PETE and NETEC have been elaborated (Fig.5 - Fig.7).

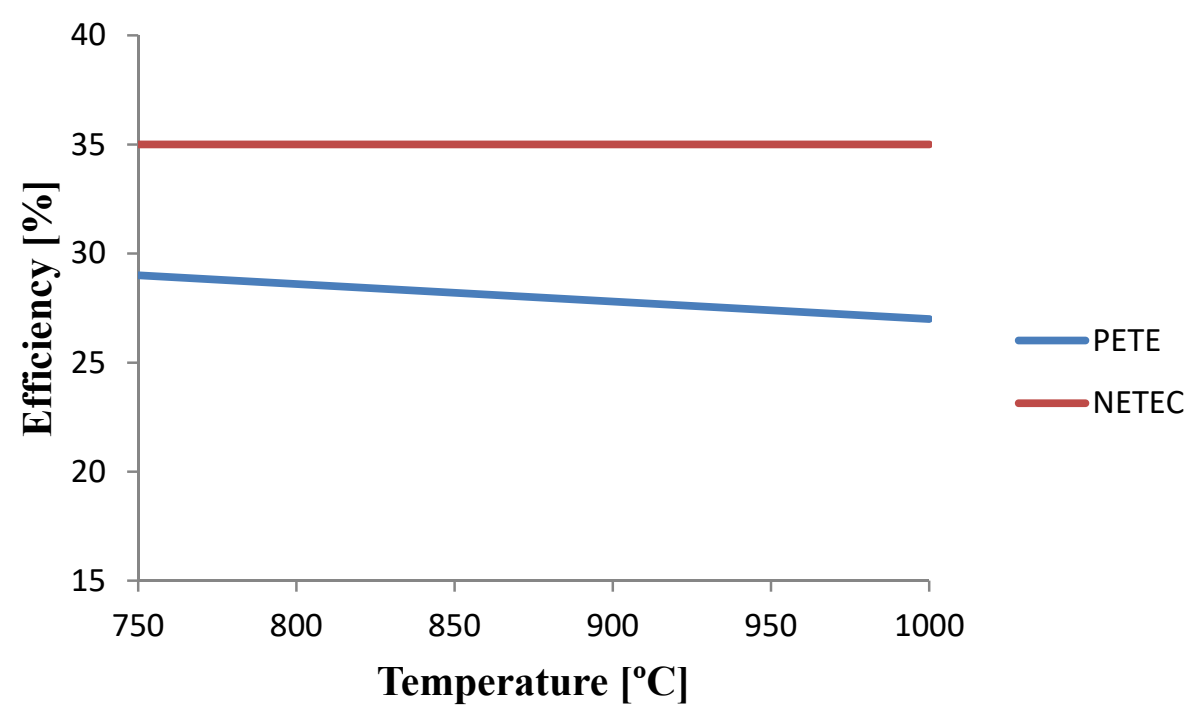

Fig. 5. The dependence of efficiency on temperature (cathode electron affinity $\chi_{C}=0.6 \mathrm{eV}$ ).

For cathode electron affinity $\chi_{\mathrm{C}}=0.6 \mathrm{eV}$, the conversion efficiency of NETEC is higher than PETE in full analysed range.

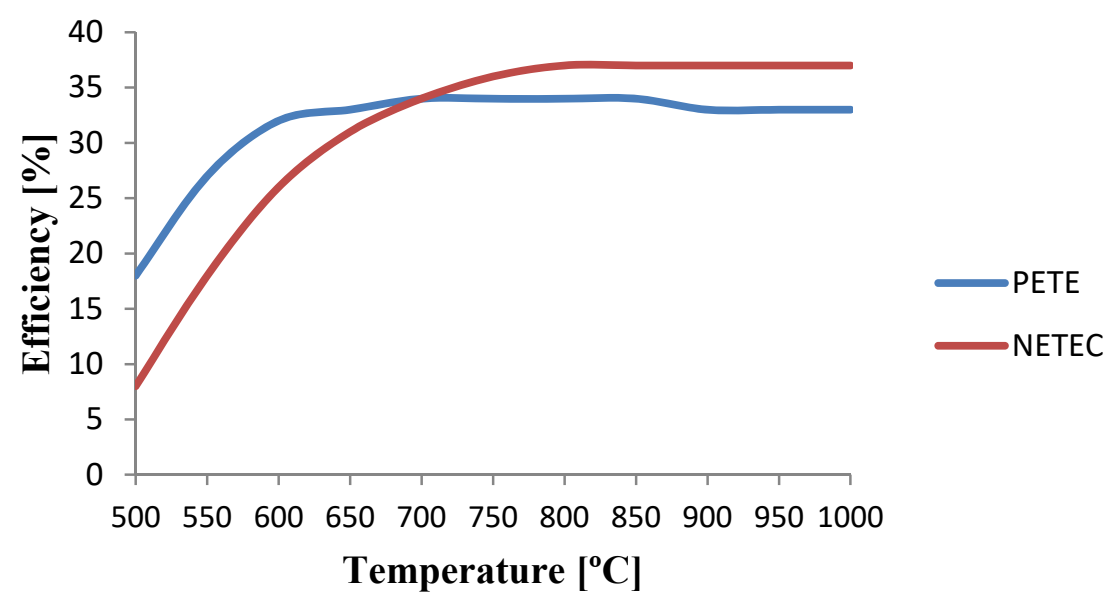

Fig. 6. The dependence of efficiency on temperature (cathode electron affinity $\chi_{C}=0.8 \mathrm{eV}$ ). 
For cathode electron affinity $\chi_{\mathrm{C}}=0.8 \mathrm{eV}$, the conversion efficiency of PETE is higher than NETEC, if temperature is below $700^{\circ} \mathrm{C}$. Above this temperature the conversion efficiency of NETEC is higher than PETE.

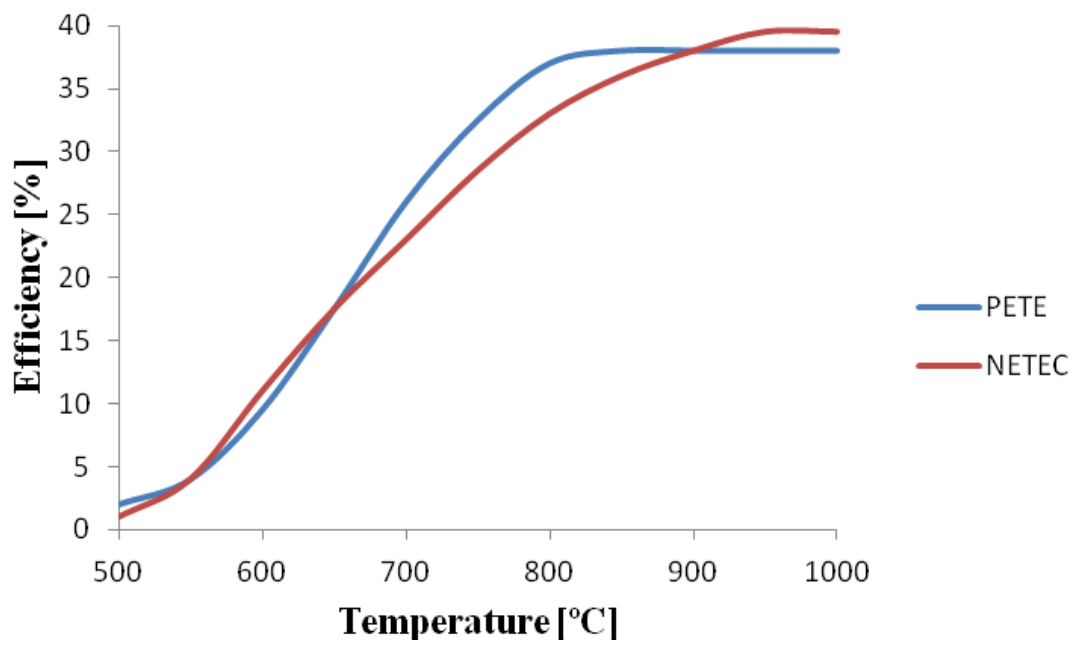

Fig. 7. The dependence of efficiency on temperature (cathode electron affinity $\chi_{C}=1 \mathrm{eV}$ ).

The above plots show that the conversion efficiency increases as the cathode electron affinity rises. Table 1 presents the features of each method $[5,9]$.

Table 1. A comparison of converting methods.

\begin{tabular}{|c|c|c|c|}
\hline & PV & PETE & NETEC \\
\hline Structure & $\begin{array}{c}\text { cathode - } \\
\text { semiconductor, } \\
\text { anode - semiconductor }\end{array}$ & $\begin{array}{c}\text { cathode - } \\
\text { semiconductor, } \\
\text { anode - metal }\end{array}$ & $\begin{array}{l}\text { cathode - } p \text {-type } \\
\text { semiconductor with } \\
\text { a low-bandgap, } \\
\text { anode - metal }\end{array}$ \\
\hline $\begin{array}{c}\text { Gap between } \\
\text { electrodes }\end{array}$ & no (PN joint) & yes (vacuum or gas) & yes \\
\hline $\begin{array}{c}\text { Working } \\
\text { temperature }\end{array}$ & relatively low & high & high \\
\hline $\begin{array}{c}\text { Influence of } \\
\text { temperature } \\
\text { increase }\end{array}$ & efficiency decreases & efficiency increases & efficiency increases \\
\hline $\begin{array}{c}\text { Light } \\
\text { concentration }\end{array}$ & $\begin{array}{l}\text { it requires a strong } \\
\text { concentration of light }\end{array}$ & $\begin{array}{l}\text { it requires a strong } \\
\text { concentration of light }\end{array}$ & not necessary \\
\hline $\begin{array}{c}\text { Solar tracking } \\
\text { system }\end{array}$ & not necessary & necessary & not necessary \\
\hline $\begin{array}{c}\text { Work in a hybrid } \\
\text { system }\end{array}$ & $\begin{array}{c}\text { for example: heating } \\
\text { system }\end{array}$ & $\begin{array}{l}\text { for example: with } \\
\text { Stirling engine }\end{array}$ & - \\
\hline $\begin{array}{c}\text { Maximum } \\
\text { efficiency }\end{array}$ & $\sim 42 \%$ & $\sim 48 \%$ & $\sim 44 \%$ \\
\hline Temperature & $\mathrm{T}_{\mathrm{A}} \approx 450 \mathrm{~K}$ & $\mathrm{~T}_{\mathrm{A}} \approx 450 \mathrm{~K}$ & $\begin{array}{c}\mathrm{T}_{\mathrm{E}}=2,000 \mathrm{~K} \\
\mathrm{~T}_{\mathrm{A}}=300 \mathrm{~K}\end{array}$ \\
\hline Work function & $\sim 1.4 \mathrm{eV}$ (cathode) & $\sim 1.4 \mathrm{eV}$ (cathode) & $0.7 \mathrm{eV}$ (anode) \\
\hline
\end{tabular}




\section{Conclusion}

PETE and NETEC systems open new ways to use solar energy in electricity generation. They reach higher conversion efficiency and do not need such advanced light concentration systems as PV cells. These new methods can generate electricity at higher temperature and exploit the solar energy to a much higher degree than PV cells. These reasons make the above solutions highly attractive. Development of PETE and NETEC systems can contribute to the growth of percentage share of renewable energy sources in total electricity generation.

\section{References}

1. T. Salmi, M. Bouzguenda, A. Gastli, A. Masmoudi, , IJRER 2(2), 214-218 (2012)

2. Z. Guanghua, Q. Min, L. Qiang, L. Dongsheng, N. Mingjiang, (Thermionic energy conversion for concentrating solar power, Applied Energy, 2017)

3. P.J. Sonneveld, G. Swinkels, B.A.J. Van Tuijl, et al., Sol Energy, 85(3), 432-442 (2011)

4. A. Segal, M. Epstein, A. Yogev, Sol Energy, 76(5), 591-601 (2004)

5. J. W. Schwede, I. Bargatin, D.C. Riley, B.E. Hardin, S.J. Rosenthal, Y. Sun, F. Schmitt, P. Pianetta, R.T. Howe, Z. Shen, N. A. Melosh, Nat. Mater., 9, 762-767 (2010)

6. J.W. Schwede, N.A. Melosh, Z. Shen, (Photon enhanced thermionic emission, USA Patent US 20100139771 A1, 2010)

7. P. Wurfel, Physics of Solar Cells, (From Basic Principles to Advanced Concepts, Wiley-VCH, Weinheim, 2009)

8. G. Segev, Y. Rosenwaks, A. Kribus, Sol. Energy Mater. Sol. Cells 140, 464-476 (2015)

9. M. Ghashami, S.K. Cho, K. Park, J. Quant. Spectrosc. Radiat. Transfer 198, 59-67 (2017)

10. J.H. Lee, I. Bargatin, N.A. Melosh, R.T. Howe, Appl. Phys. Lett. 100(17), 173904 (2012)

11. S. Meir, C. Stephanos, T.H. Geballe, J. Mannhart, J. Renew. Sustain. Energy 5(4), 043127 (2013)

12. B.Y. Moyzhes, T.H. Geballe, J. Phys. D: Appl. Phys. 38(5), 782 (2005) 